\title{
Evidence of acclimatization or adaptation in Hawaiian corals to higher ocean temperatures
}

\author{
Steve L Coles ${ }^{1,2}$ ， Keisha D Bahr ${ }^{\text {Corresp.. }}{ }^{2}$, Ku'ulei S Rodgers ${ }^{2}$, Stacie L May ${ }^{2}$, Ashley E McGowan ${ }^{2}$, Anita \\ Tsang $^{2}$, Josh Bumgarner ${ }^{2}$, Ji Hoon Han ${ }^{2}$ \\ ${ }^{1}$ Bernice Pauahi Bishop Museum, Department of Natural Sciences, Honolulu, Hawai'i, USA \\ 2 University of Hawai'i at Mānoa, Hawai'i Institute of Marine Biology, Kāne'ohe, Hawai'i, USA \\ Corresponding Author: Keisha D Bahr \\ Email address: kbahr@hawaii.edu
}

Ocean temperatures have been accelerating at an alarming rate mainly due to anthropogenic fossil fuel emissions. This has led to an increase in the severity and duration of coral bleaching events. Predicted projections for the state of reefs do not take into account the rates of adaptation or acclimatization of corals as these have not as yet been fully documented. To determine any possible changes in thermal tolerances, manipulative experiments were conducted to precisely replicate the initial, pivotal research defining threshold temperatures of corals nearly five decades ago. Statistically higher calcification rates, survivorship, and lower mortality were observed in Montipora capitata, Pocillopora damicornis, and Lobactis scutaria in the present study at $31^{\circ} \mathrm{C}$ compared to the original 1970 findings. First whole colony mortality was also observed to occur sooner in 1970 than in 2017 in M. capitata ( 3 d vs. 15 d respectively), L. scutaria ( 3 d vs. 17 d), and in $P$. damicornis ( 3 d vs. 13 d). Additionally, bleaching occurred sooner in 1970 compared to the 2017 experiment across species. Irradiance was an important factor during the recovery period for mortality but did not significantly alter calcification. Mortality was decreased by $17 \%$ with a $50 \%$ reduction in irradiance during the recovery period. These findings provide the first evidence of coral acclimatization or adaptation to increasing ocean temperatures for corals collected from the same location and using close replication of the experiment conducted nearly 50 years earlier. An important factor in this increased resistance to elevated temperature is related to removal of the discharge of treated sewage into Kāne'ohe Bay and resulting decrease in nitrification and eutrophication. However, this level of increased temperature tolerance may not be occurring rapidly enough to escape the projected increased intensity of bleaching events, as evidenced by the recent 2014 and 2015 high coral mortality in Hawai'i (34\%) and in the tropics worldwide. 


\section{Evidence of Acclimatization or Adaptation in Hawaiian Corals to 2 Higher Ocean Temperatures}

3

5

6

7

8

9

10

11

12

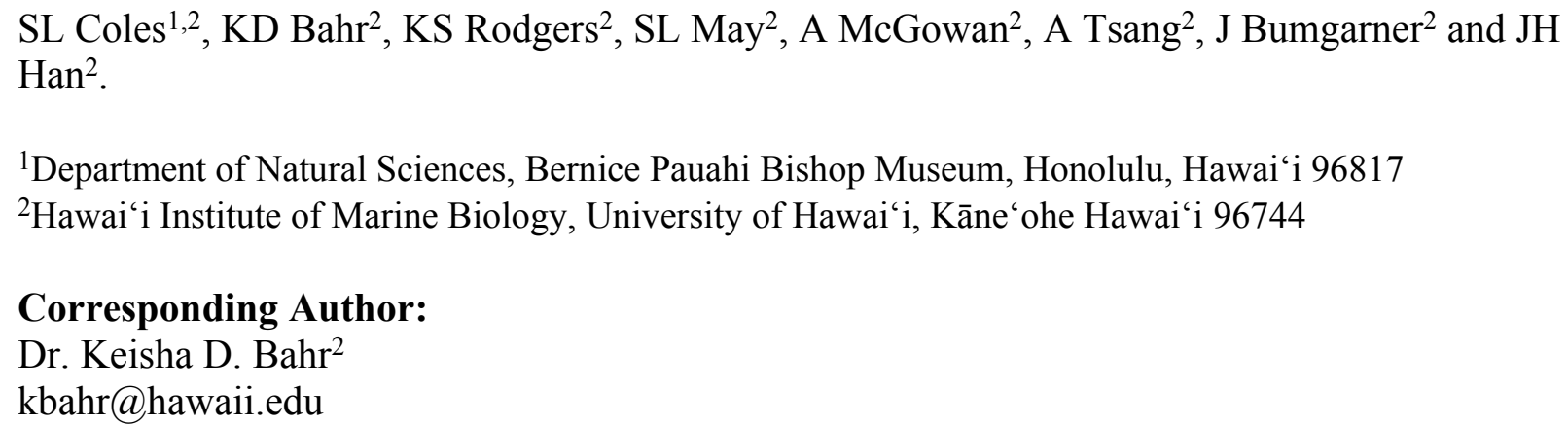


13 ABSTRACT

14 Ocean temperatures have been accelerating at an alarming rate mainly due to anthropogenic

15 fossil fuel emissions. This has led to an increase in the severity and duration of coral bleaching

16 events. Predicted projections for the state of reefs do not take into account the rates of adaptation

17 or acclimatization of corals as these have not as yet been fully documented. To determine any

18 possible changes in thermal tolerances, manipulative experiments were conducted to precisely

19 replicate the initial, pivotal research defining threshold temperatures of corals nearly five

20 decades ago. Statistically higher calcification rates, survivorship, and lower mortality were

21 observed in Montipora capitata, Pocillopora damicornis, and Lobactis scutaria in the present

22 study at $31^{\circ} \mathrm{C}$ compared to the original 1970 findings. First whole colony mortality was also

23 observed to occur sooner in 1970 than in 2017 in M. capitata ( $3 \mathrm{~d}$ vs. $15 \mathrm{~d}$ respectively), $L$.

24 scutaria ( $3 \mathrm{~d}$ vs. $17 \mathrm{~d}$ ), and in P. damicornis ( $3 \mathrm{~d}$ vs. $13 \mathrm{~d}$ ). Additionally, bleaching occurred

25 sooner in 1970 compared to the 2017 experiment across species. Irradiance was an important

26 factor during the recovery period but did not significantly alter calcification. Mortality was

27 decreased by $17 \%$ with a $50 \%$ reduction in irradiance during the recovery period. These findings

28 provide the first evidence of coral acclimatization or adaptation to increasing ocean temperatures

29 for corals collected from the same location and using close replication of the experiment

30 conducted nearly 50 years earlier. An important factor in this increased resistance to elevated

31 temperature is related to removal of the discharge of treated sewage into Kāne 'ohe Bay and

32 resulting decrease in nitrification and eutrophication. However, this level of increased

33 temperature tolerance may not be occurring rapidly enough to escape the projected increased

34 intensity of bleaching events, as evidenced by the recent 2014 and 2015 high coral mortality in

35 Hawai'i (34\%) and in the tropics worldwide.

\section{INTRODUCTION}

Coral reef ecosystems have high biological value and are critical to the health and livelihoods of human communities throughout the tropical oceans. Commonly called the 'rainforests of the sea', coral reefs occupy $0.17 \%$ of the world's ocean area (Smith, 1978), yet support more than $33 \%$ of all marine species (Fisher et al., 2015). The increasing frequency and severity of coral bleaching events is placing these critical habitats under imminent threat, with some models projecting the collapse of reefs worldwide once climate change exceeds $1-2^{\circ} \mathrm{C}$ above the preindustrial ocean temperatures, a value certain to be exceeded by the end of the century (Hoegh-Guldberg, 1999; Frieler et al., 2012).

Coral bleaching is a term first used by Vaughan (1911) to describe the results of low tide exposure of corals at the Tortugas. However, what Vaughan observed was not coral bleaching but mortality and exposure of bare coral skeleton.

Yonge and Nicholls (1931) described coral bleaching following temperature increases up to $37^{\circ} \mathrm{C}$ in coral pools at the Low Isles, Great Barrier Reef that resulted in the loss of the intracellular symbiotic algae zooxanthellae. If this symbiosis is disrupted for extended periods, pigment loss and eventual mortality will occur (Jokiel and Coles, 1990; Williams and BunkleyWilliams, 1990; Glynn, 1991, 1993; Brown, 1997; Wilkinson et al., 1998; Boesch et al., 2000; Fitt et al., 2001; Coles and Brown, 2003; Hughes et al., 2003, 2017; Hoegh-Guldberg et al., 2007). The first recent documented widespread bleaching event occurred in 1983 off Panama (Glynn, 1991; Graham, 1994), followed by frequent and severe events around the world in 1998 and 2010, (http://www.noaanews.noaa.gov/stories2015/100815-noaa-declares-third-ever-global- 
65

coral-bleaching-event.html). The most recent worldwide bleaching event lasted from 2014 to 2017, the longest, most widespread, and possibly the most damaging coral bleaching on record (Hughes et al., 2017). More than 70\% of coral reefs around the world experienced heat stress related to bleaching and/or mortality during the three-year global event (https://coralreefwatch.noaa.gov/satellite/analyses_guidance/global_coral_bleaching 201417_status.php, Eakin et al., 2017).

Average offshore Sea Surface Temperatures (SSTs) in Hawai'i have steadily increased a significant $1.13^{\circ} \mathrm{C}$ over the last 47 years $(1958-2014)$ (Fig. 1). The first documented widespread bleaching event in the main Hawaiian Islands occurred in 1996 in Kāne'ohe Bay (Jokiel and Brown, 2004), followed by major events in 2002 and 2004 in the Northwestern Hawaiian Islands (Aeby et al., 2003; Jokiel and Brown, 2004; Kenyon et al., 2006) and minor bleaching events in 2007 and 2009. These bleaching events were short in duration, and coral communities recovered rapidly once temperatures returned to normal. However, in 2014 and 2015, the Hawaiian Archipelago experienced unprecedented widespread bleaching and mortality with well over half of the corals exhibiting bleaching and a mean mortality of 34\% (Kramer et al., 2016; SSRI, 2017; Couch et al., 2017; Coles, 2017; Bahr and Rodgers, 2017; Rodgers et al., 2017).

In the 1970s, threshold temperatures initiating bleaching of Hawaiian corals were determined in a series of pioneering studies using a manipulative flow through seawater system and field observations (Coles, 1973; Jokiel and Coles, 1974, 1977; Coles and Jokiel, 1977,1978). This research compared thermal tolerances for Kāne'ohe Bay corals and Eniwetok coral congeners and conspecifics and found similar thresholds of $+1-2^{\circ} \mathrm{C}$ above summer ambient to induce bleaching, indicating corals worldwide to be living within $1-2^{\circ} \mathrm{C}$ of their upper limit during summer months. This $1-2^{\circ} \mathrm{C}$ bleaching threshold has since been observed across the geographic range that corals inhabit, even though maximum seasonal temperature among regions varies by up to $9^{\circ} \mathrm{C}$, from $25^{\circ} \mathrm{C}$ at Rapa Nui to $33-34^{\circ} \mathrm{C}$ in the Arabian Gulf (Coles and Brown, 2003; Jokiel, 2004; Jokiel and Brown, 2004; Coles and Riegl, 2013). This seminal research on coral temperature thresholds has been and continues to be used in numerous management applications and modeling projections, including the primary NOAA Coral Reef Watch satellite monitoring and modeled outlook program (Liu et al., 2014). Since both the magnitude of thermal stress and the duration are key factors in bleaching response, the Coral Reef Watch has developed a thermal stress index, the Coral Bleaching Degree Heating Week (DHW), that takes both of these factors into account.

Irradiance is another key factor that determines the extent of bleaching (Coles, 1973; Jokiel and Coles, 1977; Coles and Jokiel, 1978; Brown et al., 2000) and is often correlated with high temperatures which occur during the summer when irradiance is at its maximum (HoeghGuldberg and Smith, 1989; Goenaga and Canals, 1990; Fitt and Warner, 1995; Brown et al., 1999; Jokiel, 2004). Individual corals typically show more pronounced bleaching and mortality on upper surfaces of the colony exposed to higher irradiance (Jokiel and Coles, 1977) as do shallower corals exposed to higher irradiance than their deeper counterparts (Jokiel, 2004).

Projections of future climate change have led many to conclude that globally coral reefs could collapse within the next few decades (Hoegh-Guldberg, 1999; Hoegh-Guldberg et al., 2007; Veron et al., 2009; Frieler et al., 2012). The upper thermal tolerance thresholds of corals 
105 throughout the world could be exceeded every summer by the year 2030 (Hoegh-Guldberg,

106 1999). However, many of these projections do not consider the potential for acclimation,

107 acclimatization, or adaptation (Coles and Brown, 2003; Berkelmans and van Oppen, 2006).

108 Acclimation refers to changes in tolerances under laboratory or other experimental conditions,

109 generally over the short-term (Coles and Brown, 2003). Acclimatization refers to phenotypic

110 changes by an organism to stresses in the natural environment that result in the readjustment of

111 an individual organism's tolerance levels within the organism's lifetime as it adjusts to a change

112 in the environment. Adaptation is a selective process that may take place over one or many

113 generations when the more stenotopic members of a population are eliminated by environmental

114 stress, leaving the more tolerant organisms to reproduce and recruit to available habitat. Many

115 assume that adaptation is inherently a slow process requiring thousands to millions of years, and

116 that corals will show little adaptive response to the rapid climate change occurring today (Brown,

117 1997; Gates and Edmunds, 1999; Hoegh-Guldberg, 1999; Hoegh-Guldberg et al., 2007; Veron et

118 al., 2009; Frieler et al., 2012). However, rapid genetic adaptation to temperature in Acropora

119 millipora has been predicted through simulations of higher latitude migration of heat tolerant

120 alleles (Matz et al., 2018). In this paper we will refer to a shift in thermal tolerance as

121 acclimatization/adaptation as it is not within the realm of this research to differentiate between

122 them.

123

124

125

126

127

128

129

130

131

132

133

134

135

136

137

138

139

140

141

142

While Hughes et al. $(2017,2018)$ found little evidence to support acclimatization/adaptation of corals to thermal stress related coral bleaching from previous events, there have been numerous reports throughout the world of reduced bleaching and mortality by corals exposed to previous bleaching in the Arabian Gulf (Riegl, 2003), Great Barrier Reef (Maynard et al., 2008; Guest et al., 2012), Caribbean (Castillo et al., 2012), Moorea, French Polynesia (Pratchett et al., 2013), Kiribati (Carilli et al., 2012) and the Northwestern Hawaiian Islands (Couch et al., 2017). Other studies indicate that acclimatization or adaptation to increased temperature is possible in many coral species. Coral species in similar habitats have shown different bleaching susceptibilities, indicating that some coral species and even individuals within species are more resistant to environmental stressors than others (Baird and Marshall, 2002; Stimson, et al., 2002; Grottoli, et al., 2004). Also, the adaptation in thermal tolerance corresponding to local ambient temperatures worldwide is an indication of long-term selection for more temperature tolerant corals determined by a region's thermal history (Jokiel and Coles 1990, Coles and Brown, 2003). However, rates of acclimatization/adaptation to projected rapid climate change and escalating stress from rising seawater temperatures have not been determined. Lacking specific experimental information, a mathematical model by Donner et al. (2005) has proposed that bleaching will become an annual event in the next 30-50 years without an increase in thermal tolerance of $0.2-1.0^{\circ} \mathrm{C}$ per decade. Genomic model simulations by Bay et al. (2017) suggest that corals have sufficient genetic variability for rapid evolution of heat tolerance for survival under mild ocean warming but may undergo extinction under high $\mathrm{CO}_{2}$ emissions. Logan et al. (2014) modeled possible adaptive responses in corals and found that an adaptive increase in bleaching thresholds would delay bleaching occurrence by only 10 additional years.

Kāne 'ohe Bay has some of the highest coral cover in Hawai' $i$, but has historically been $1-2^{\circ} \mathrm{C}$ higher in the summer months than most other reef areas in Hawai ' $i$ due to restricted circulation (Jokiel et al., 2004; Franklin et al., 2013; Bahr et al., 2015a). Additionally, the coral reefs of Kāne'ohe Bay have been surprisingly resilient over decadal timescales following numerous 
151 events that drastically reduced live coral cover (Bahr et al., 2017). The gradual rise in open ocean water temperatures of nearly $1^{\circ} \mathrm{C}$ over the last 50 years (Fig. 1), and the occurrence of three major bleaching events in Kāne'ohe Bay that were followed by high recoveries of the dominant reef building corals provided a unique opportunity to assess whether acclimatization/adaption of these corals has occurred. To assess possible changes in thermal tolerances we replicated experiments conducted in 1970 that first defined the long-term thermal tolerances of corals (Coles, 1973; Jokiel and Coles, 1974; Coles et al., 1976; Jokiel and Coles, 1977; Coles and Jokiel, 1978). Ambient temperature in the experiments in $1970\left(26.4^{\circ} \mathrm{C}\right)$ was $2.2^{\circ} \mathrm{C}$ lower than in the current 2017 experiments $\left(28.6^{\circ} \mathrm{C}\right)$. We thus exposed corals to temperatures $2.8^{\circ} \mathrm{C}$ above ambient to replicate the increase in temperature above ambient in the 1970 experiments. Replication was also controlled through identical methodology, location, seawater system, and observer. Results are evaluated in terms of the long-term potential for upward adjustments of thermal thresholds for coral bleaching and interspecific differences among species for capacity to change.

\section{METHODOLOGY}

The experiments conducted in 1970 and 2017 were conducted in the identical fiberglass flowthrough mesocosms exposed to full sunlight at the same coral reef ecology laboratory. This open flow experimental system assures a representative environment to track biological response under natural conditions (Jokiel et al., 2014). Corals were collected from shallow Kāne'ohe Bay reef flats (collection permit DAR SAP 2018-03) at depths approximately equal to the $0.5 \mathrm{~m}$ deep mesocosms, therefore the unshaded light intensity in the mesocosms are nearly identical to the light corals experience in the field (Jokiel and Coles, 1977). In our 2017 experiment, we examined the interaction between irradiance and temperature (ambient temperature, $+2.8^{\circ} \mathrm{C}$ above ambient), with full natural light intensity and shading $(50 \%)$ for both temperature treatments. Six $1 \mathrm{~m} \times 1 \mathrm{~m}$ mesocosms ( $\mathrm{n}=3$ per temperature treatment), and a water delivery system with flow rates identical to the ones designed by the original authors were used in this experiment. The seawater intake is located $20 \mathrm{~m}$ from the experimental site at a depth of $2 \mathrm{~m}$.

To replicate the original thermal tolerance experiments conducted in 1970 (Coles et al., 1976; Jokiel and Coles, 1977; Coles and Jokiel, 1978)), three species of corals, Montipora capitata (previously M. verrucosa), Pocillopora damicornis, and Lobactis scutaria (previously Fungia scutaria),(Gittenberger et al., 2011) were collected from the Moku o Lo'e reef in Kāne'ohe Bay, $\mathrm{O}^{\prime} \mathrm{ahu}$, near the original 1970 experiment collection site $\left(21.4^{\circ} \mathrm{N}, 157.8^{\circ} \mathrm{W}\right)$. The endemic species, Porites compressa, was added in 2017 to compare thermal tolerance of the most abundant coral in the bay but had not been tested in the 1970 experiment due to parasitism of Phestilla sibogae that was uncontrollable at that time. These species represent the diversity of common Hawaiian corals. Porites compressa, is a gonochoristic broadcast spawner and shows traits associated with both stress-tolerant and competitive life history strategies (Hunter, 1988). Montipora capitata is a hermaphroditic broadcast spawner and shows a competitive life history strategy (Kolinski, 2004; Padilla-Gamino et al., 2014). Pocillopora damicornis engages in brooding as well as broadcast spawning and shows a weedy life history strategy but reaches a determinate size (Richmond and Jokiel, 1984; Richmond and Hunter, 1990). Unlike these three dominant reef-builders, Lobactis scutariais a solitary ahermatypic coral that can be abundant on Kāne'ohe Bay reefs (Darling et al., 2012). During the first bleaching event observed in Kāne'ohe Bay in 1996 and later events in 2014 and 2015, L. scutaria was one of the most resistant to 
197 bleaching; $P$. compress $a$ and $M$. capitata showed moderate resistance to bleaching, and $P$.

198 damicornis showed high levels of susceptibility to bleaching (Brown and Jokiel, 2004; Bahr et

199 al., 2015b).

200

201

\section{Experimental Conditions}

202 Twenty colonies of each species were placed in each of the six aerated 660-liter mesocosms, for

203 a total of 480 colonies, and weighed using the buoyant weighing technique (Jokiel, et al., 1978).

204 All colonies were placed on white styrene lighting panels and elevated $5 \mathrm{~cm}$ off the bottom to

205

206

207

208

209

210

211

212

213

214

215

216

217

218

219

220

221

222

223

224

225

226

227

228

229

230

231

232

233

234

235

236

237

238

239

240

241

242 reduce sediment collection on corals and facilitate fish cleaning. Each individual coral was tagged using a Dymo $\odot$ labeler and attached with plastic coated wire. To avoid damage to the solitary L. scutaria labels were affixed to the bottom of each coral using ZSPAR A-788 nonvolatile Splash Zone compound. Corals were divided into two groups for shading, randomly placed within each section and mesocosm, and allowed to acclimate to conditions for a period of two weeks at ambient mean temperatures of $28.6^{\circ} \mathrm{C}$. Half of each tank was covered with a frame of $50 \%$ shade cloth to simulate depth $(\sim 2.5 \mathrm{~m})$ while the other half remained uncovered in full sunlight. Shading was evaluated using a LiCor LI-250A light meter.

To control settlement and growth of the nudibranch Phestilla sibogae, which feeds on Porites compressa, and the flatworm Prostiostomum montiporae, that preys on Montipora capitata, one adult Chaetodon auriga (IACUC permit \# 2620) was placed in each of the six mesocosms. To reduce algal growth, one adult Acanthurus triostegus was placed in each mesocosm. Daily addition of frozen brine shrimp supplemented fish feedings. To supplement parasitism control, twice weekly manual cleaning of Phestilla eggs and adults was conducted.

Onset ${ }^{\mathrm{TM}}$ Pro v2 temperature loggers with an accuracy of $\pm 0.21^{\circ} \mathrm{C}$ from $0^{\circ}$ to $50^{\circ} \mathrm{C}$ and a drift of $1 \% \mathrm{yr}^{-1}$ were calibrated at $0^{\circ} \mathrm{C}$ and $35^{\circ} \mathrm{C}$ prior to placement in each mesocosm. Loggers were set to record at 15-minute intervals throughout the duration of the experiment. Flow rates were calibrated between mesocosms for a turnover rate of approximately one hour and reassessed weekly throughout the eight-week experiment. Following the acclimation period, three replicate mesocosms remained under ambient conditions. One 800-watt Finnex titanium heater and two 1000-watt Blue Line IPX8 titanium heaters were positioned in each of the remaining three mesocosms to assure even heating to $31.4^{\circ} \mathrm{C}$, an increase of $2.7^{\circ} \mathrm{C}$ above ambient conditions for the 31-day experimental period (12 Jul - 11 Aug 2017). AquaClear powerhead multifunctional water pumps and rapid turnover rates assured consistency among corals. All heaters were removed prior to the 28-day recovery period (12 Aug - 8 Sept 2017).

\section{Environmental Variables}

Long-term sea surface temperature trends from the Koko Head site were downloaded from Integrated Global Ocean Services System-National Meteorological Center (http://iridl.ldeo.columbia.edu/SOURCES/.IGOSS/.nmc/.Reyn_SmithOIv2/.weekly/.sst/). The HIMB meteorological station located on site provided UV, PAR, total solar, wind direction and speed, air and water temperatures, and precipitation data (available at http://www.pacioos.hawaii.edu/weather/obs-mokuoloe/). Salinity, temperature, and dissolved oxygen were measured daily in each mesocosm using a YSI 556 MPS multimeter (Table 1). Historical environment parameters were compiled from previous studies (Smith et al., 1981; Cox et al., 2006) for comparison. These values were derived from previous studies with temporal and 
243 spatial measurements closest to the 1970 experiment and prior to the sewage diversion in 1977

244 through 1979 (Table 1). Mesocosm ambient temperatures were $2.2^{\circ} \mathrm{C}$ higher in 2017 than in

2451970 during the same July-August periods. Salinity (ppt), PAR (k), and Total N\&P ( $\mu$ Mol/L) not

246 measured in the mesocosms in 1970 were obtained from measurements taken in 1976-1977 in

247 the adjacent South Bay (Smith et al., 1981) and compared to values from 1998-2001 (Cox et al.,

250

251

252

253

254

255

256

257

258

259

260

261

262

263

264

265

266

267

268

269

270

271

272

273

274

275

276

277

278

279

280

281

282

283

284

285

286

287

288

\section{Calcification}

The initial and final buoyant weights were converted to dry skeletal weight for each species (Jokiel et al., 1978). These data were expressed as the mean solid radius, which uses cube-root approximation to compute a one-dimension linear estimate. Therefore, the calcification rate is expressed as a change in length of the radius rather than the weight change. This transformation compensates and permits for comparison of colony calcification independent of corallum sizes and morphology (Maragos, 1978).

\section{Partial Mortality}

Partial mortality was defined as percentage of dead skeletal area on each coral colony throughout the 31-day experimental period and subsequent 28-day recovery period. Partial mortality was scored in bins of $10 \%$ twice weekly. Values ranged from zero (no mortality) through various amounts of tissue loss (partial mortality) to 100\% (whole-colony mortality) (Baird and Marshall, 2002). Survivorship was characterized by the number of individuals alive within a treatment during the experimental and recovery period. These data were used to compare the 2017 with the 1970 results.

\section{Visual Assessments}

Visual assessments of condition of corals in all treatments were made by author SLC, who collaborated in the 1970s experiment observations (Coles and Jokiel, 1978) or personally conducted these observations (Coles, 1973; Jokiel and Coles, 1974; Coles et al., 1976; Coles and Jokiel, 1978). During the elevated temperature phase of the present experiment that lasted 31 days, observations of coral mortality and pigmentation were made in both heated and ambient tanks at approximately the same frequency as recorded by Jokiel and Coles (1977) (i.e. 2-3 times per week during the first two weeks, twice a week during the third week and once a week during the fourth week). Following temperature reduction to ambient in all tanks, corals were observed approximately weekly for another 28 days to determine any recovery that might occur.

The original 1970 experiment used four categories to describe coral condition: Normal, pale, bleached, and dead. The appearance of these has been previously described in Jokiel and Coles (1974). Images of the four stages of pigmentation are available in Fig. S1.

\section{Statistical Approach}

\section{Experiment}

Mean mid-day water temperatures within treatment mesocosms were analyzed using a one-way ANOVA during the experimental and recovery periods. Percentage data for partial mortality at the end of the experimental (11 Aug 2017) and recovery phases (8 Sept 2017) were transformed using an arcsine cubed root transformation and subsequently analyzed with a three-way ANOVA 
289

290

291

292

293

294

295

296

297

298

299

300

301

302

303

304

305

306

307

308

309

310

311

312

313

314

315

316

317

318

319

320

321

322

323

324

325

326

327

328

329

330

331

332

333

334

model with fixed factors of temperature, irradiance level, and species. Assumptions of normal distribution and homoscedasticity were assessed through graphical analyses of the residuals. An unbalanced design was used to account for an imbalance in sample size between the shaded and unshaded treatments due to a technical error. Type III sums of squares estimated the main effect of the squared differences of the unweighted marginal means.

Coral calcification at the end of the experimental period (Day 31) was analyzed using a General Linear Model (GLM). Corals subjected to high levels of partial mortality ( $>50 \%$ tissue loss) at the end of the 31-day experiment were removed from the GLM calcification analysis. Type III sums of squares were used to estimate the main effect of the squared differences of the unweighted marginal means. Descriptive and statistical analyses were conducted in JMP Pro 12 (SAS Institute Inc. USA).

Comparison of 1970 vs 2017 experiments

The long-term open-ocean Koko Head temperature trends (Integrated Global Ocean Services System-National Meteorological Center (http://iridl.ldeo.columbia.edu/SOURCES/.IGOSS/.nmc/.Reyn_SmithOIv2/.weekly/.sst/) between 1970 and 2017 were analyzed using a linear regression and mean sea surface temperatures with a One-way ANOVA.

Coral survivorship at heated temperatures $\left(31^{\circ} \mathrm{C}\right)$ was analyzed using a cox proportional hazards regression analysis by year, with censoring of individuals that survived to the end of the experiment. Coral time to mortality was recorded as the number of days since the start of the experiment within each year. Wilcoxon rank-sum test was used to compare the average number of day until the onset of bleaching and whole-colony mortality between years within species.

\section{RESULTS}

\section{Experiment}

\section{Experimental Conditions}

During the 2017 experimental period (11 Jul - 11 Aug 2017), the corals received full natural solar radiation at mid-day maximum irradiance levels of $1745 \mu \mathrm{mol}$ photons $\mathrm{m}^{-2} \mathrm{~s}^{-1}$ and mean net irradiance fluxes of $749.18 \mu \mathrm{mol}$ photons $\mathrm{m}^{-2} \mathrm{~s}^{-1}$. Within treatments of temperature (mean midday temperatures) were not significantly different between mesocosms (One-way ANOVA; F $(2,53)=1.28 ; p=0.27)$. Experimental mesocosms were heated to a mean of $31.40 \pm 0.015^{\circ} \mathrm{C}$ and ambient conditions were $28.62 \pm 0.015^{\circ} \mathrm{C}$ (Table 1). Heaters were removed from the mesocosms on 11 Aug 2017 and the recovery period commenced (12 Aug - 8 Sept 2017). Temperatures did not differ among mesocosms during the recovery period (Oneway ANOVA; $\mathrm{F}(5,185)=1.80 ; p$ $=0.12$ ).

\section{Calcification}

Compared to the control treatment $\left(28.6^{\circ} \mathrm{C}\right)$, increased temperatures $\left(31.4^{\circ} \mathrm{C}\right)$ significantly reduced calcification rates (pooled among irradiance; mean difference \pm SE) in Montipora capitata $\left(-63 \% ;-3.03 \pm 0.26 \mathrm{~mm} \mathrm{~d}^{-1} ; p<0.0001\right)$, Pocillopora damicornis $(-55 \% ;-1.85 \pm 0.29 \mathrm{~mm}$ $\left.\mathrm{d}^{-1} ; p<0.0001\right)$, Porites compressa $\left(-51 \% ;-2.09 \pm 0.31 \mathrm{~mm} \mathrm{~d}^{-1} ; p<0.0001\right)$, and Lobactis scutaria $\left(-26 \% ;-0.99 \pm 0.25 \mathrm{~mm} \mathrm{~d}^{-1} ; \mathrm{p}<0.0001\right)$ (General Mixed Model; $\left.\mathrm{F}_{(11,390)}=21.58 ; p<0.0001\right)$ (Fig. 
335 2). Calcification response did not vary across irradiance levels $(\mathrm{p}=0.442)$. Once the heat stress

336 was removed, the decline of calcification rates continued with reductions of $-89 \%$ (mean

337 difference; $-1.23 \pm 0.26 \mathrm{~mm} \mathrm{~d}^{-1}$ ) across species (General Mixed Model; $\mathrm{F}_{(15,295)}=2.756$;

$338 p<0.0001$.

339

340

341

342

343

344

345

346

347

348

349

350

351

352

353

354

355

356

357

358

359

360

361

362

363

364

365

366

367

368

369

370

371

372

373

374

375

376

377

378

379

\section{Partial Mortality and Recovery}

Elevated temperatures caused high rates of tissue loss (mean \pm SE) leading to significant increases in exposed dead skeleton (pooled among light levels) in Lobactis scutaria (12 \pm $0.04 \%)$, Pocillopora damicornis ( $51 \pm 0.06 \%)$, Montipora capitata $(28 \pm 0.05 \%)$, and Porites compressa $(60 \pm 0.06 \%)$ at the end of the experimental phase (Three-way ANOVA; $\mathrm{F}(15,437)=$ $16.45 ; p<0.0001)$ (Fig. 3).

The progressive bleaching and mortality during the experimental phase of the study continued into the recovery phase after temperatures returned to ambient (Fig. 3). At the end the recovery phase partial mortality varied among species. In heated treatments, the lowest partial mortality was observed in L. scutaria (18\%) followed by M. capitata (79\%), P. compressa (89\%), and $P$. damicornis (93\%) (species*temperature, $p<0.0001$; pooled across irradiance levels). Irradiance level (shading vs. unshaded) also played a role in partial mortality during the recovery phase $(p=0.016)$. Unshaded corals had $17 \%$ higher mortality than shaded corals (Three-way ANOVA; $\mathrm{F}(15,446)=64.96 ; p<0.0001)$ (Fig. 3).

\section{Comparison of 1970 vs 2017 experiments}

\section{Environmental Variables}

Offshore mean yearly sea surface temperatures (SST) have increased by $1.13^{\circ} \mathrm{C}$ over the past 47 years $\left(\mathrm{R}^{2}=0.06, \mathrm{~F}_{(1,4506)}=288.01, p<0.0001\right)$ (Fig. 1). This increase in SST has created a shifting baseline for comparison of the Jokiel and Coles 1970 experiment with the current experiment. Summer (July-August) mean mid-day ambient temperatures between $1970\left(26.4^{\circ} \mathrm{C}\right)$ and $2017\left(28.6^{\circ} \mathrm{C}\right.$ ) differed by $2.2^{\circ} \mathrm{C}$ (Oneway ANOVA; $\left.\mathrm{F}_{(1,21)}=10.66 ; p=0.0039\right)$ (Table 2).

Temperature variability was slightly greater for the 1970 experiments (e.g., see Coles and Jokiel, 1978; Table 1) where standard deviation (SD) in four tanks of one experimental series ranged $0.9-1.2^{\circ} \mathrm{C}$, while $\mathrm{SD}$ for the 2017 experiment ranged from $0.36-0.45^{\circ} \mathrm{C}$ in ambient tanks and $0.32-0.36^{\circ} \mathrm{C}$ in stress temperature tanks (Table 2 ). These differences in temperature variability are trivial when compared with the mean temperatures of the treatments.

\section{Calcification}

During the 1970 experiment, elevated temperatures had a significant impact on calcification rates across species (-99\% Lobactis scutaria; $-164 \%$ Montipora capitata; $-172 \%$ Pocillopora damicornis) in comparison to ambient temperatures $\left(26.4^{\circ} \mathrm{C}\right)$ (Fig. 4). When compared to replicated conditions in the 2017 experiment, less severe reductions in calcification rates occurred. Elevated temperatures under ambient irradiance conditions reduced calcification by $8 \%$ in L. scutaria, $-50 \%$ in M. capitata, and $-16 \%$ in P. damicornis (Fig. 4, Table 3).

\section{Survivorship}

Coral survivorship at elevated temperature $\left(\sim 31.4^{\circ} \mathrm{C}\right)$ was higher in 2017 across species: $L$. scutaria $(92 \% ; p<0.0001)$, M. capitata $(83 \% ; p<0.0001)$, and $P$. damicornis $(60 \% ; p=0.0003)$ 
380 (Cox Proportional Hazards Regression Analysis; Fig. 5; Table 3, S1). Lower surivorship was

381

382

383

384

385

386

387

388

389

390

391

392

393

394

395

396

397

398

399

400

401

402

403

404

405

406

407

408

409

410

411

412

413

414

415

416

417

418

419

420

421

422

423

424

425

observed at $31^{\circ} \mathrm{C}$ in $1970(40 \%$ L. scutaria; $0 \%$ M. capitata; $5 \%$ P. damicornis $)$.

Additionally, whole-colony mortality was observed sooner, just after 3 days of exposure to $31^{\circ} \mathrm{C}$, in 1970 (i.e., . damicornis, $\mathrm{n}=15$; M. capitata, $\mathrm{n}=8$; and L. scutaria, $\mathrm{n}=3$ ) (Jokiel et al., 1975) (Wilcoxon rank-sum test: L. scutaria $p<0.0001$; M. capitata $p<0.0001$; $P$. damicornis $\mathrm{p}<0.0001$ ). Corals were able to withstand elevated temperatures $\left(31.4^{\circ} \mathrm{C}\right)$ for a longer period of time in the current 2017 experiment. Entire colony death was first observed in P. damicornis $(\mathrm{n}=1)$ after 13 days, in M. capitata $(\mathrm{n}=1)$ after 15 days and in L. scutaria $(\mathrm{n}=1)$ after 17 days (Fig. 5).

\section{Visual Assessment}

In 1970, onset of bleaching was observed after 3 days of exposure to elevated temperatures $\left(31.0^{\circ} \mathrm{C}\right)$ in $P$. damicornis $(\mathrm{n}=2), M$. capitata $(\mathrm{n}=8)$, and bleaching was observed after 5 days in L. scutaria $(\mathrm{n}=7)$. Bleaching was prolonged during the 2017 experiment (Wilcoxon rank-sum test: $L$. scutaria $p=0.0002 ;$ M. capitata $p<0.0001$; . damicornis $p=0.0002$ ). Initial bleaching was observed after 6 days of exposure to $31.4^{\circ} \mathrm{C}$ in M. capitata $(\mathrm{n}=1)$ and $P$. damicornis $(\mathrm{n}=1)$. Full bleaching was observed in L. scutaria $(\mathrm{n}=1)$ after 8 days of elevated temperature.

These differences of progressive patterns of bleaching and mortality are indicated by the visual assessment average scores shown in Fig. 6. All three species showed more rapid bleaching and mortality in 1970 than in 2017, with complete mortality occurring for $M$. capitata and $P$. damicornis by 12 days at $31^{\circ} \mathrm{C}$ in 1970 , which did not occur for either species at $31.4^{\circ} \mathrm{C}$ by the end of the experimental period.

\section{DISCUSSION}

Little is known about the potential for corals to acclimatize/adapt to the rapid pace of climate change. This research assessed the potential for a shift in thermal tolerances of Hawaiian corals over the past half century by replicating the experimental design and using the same observer as in the original 1970 experiment. Although acclimatization/adaptation to increasing local ambient temperatures has occurred in corals globally over the long term in different geographic environments (Coles and Brown, 2003), the rate of acclimatization/adaptation has not been previously determined for rapid temperature increases that occur in severe bleaching events. Our experiments are the first to demonstrate thermal acclimatization/adaptation to elevated ocean temperature for corals of the same species and from the same location over the past half century.

Our results show significant differences in coral bleaching, calcification, survivorship, and mortality since 1970 in three species of corals (Lobactis scutaria, Montipora capitata, Pocillopora damicornis). These corals show higher calcification rates at a similar temperature increase in 2017 as compared to 1970. Calcification rates remained impaired under elevated temperatures across species; however, the reductions in 2017 were not as severe as those documented in 1970. When we compared reductions in calcification rates due to elevated temperatures across years, we found that calcification rates were 70-90\% higher in 2017 (Table $3)$. Similarly, mean mortality across species was substantially reduced in $2017(22 \%)$ as compared to $1970(85 \%)$. In 1970 , mortality was high after $30 \mathrm{~d}$ of exposure to $31^{\circ} \mathrm{C}$ across species (Fig. 5). We observed significantly higher survivorship among species after $31 \mathrm{~d}$ at 
426

427

428

429

430

431

432

433

434

435

436

437

438

439

440

441

442

443

444

445

446

447

448

449

450

451

452

453

454

455

456

457

458

459

460

461

462

463

464

465

466

467

468

469

470

471 $31.4^{\circ} \mathrm{C}$ (Table 3 ). First whole colony mortality was also observed to occur sooner in 1970 than in 2017 in M. capitata ( $3 \mathrm{~d}$ vs. $15 \mathrm{~d}$ respectively), L. scutaria ( $3 \mathrm{~d}$ vs. $17 \mathrm{~d}$ ), and in P. damicornis (3 d vs. 13 d). In 2017, calcification continued to decline during the recovery period suggesting allocation of resources from growth to repair (Henry and Hart, 2005). Unfortunately, no recovery measurements were reported from 1970. Supporting evidence of acclimatization/adaptation was also observed in the qualitative bleaching assessments. Bleaching was reported much sooner in 1970 as compared to 2017 at similar temperatures (Fig. 6). In 1970, onset of bleaching occurred in half the number of days ( $3 \mathrm{~d})$ than in 2017 (6 d) in P. damicornis and M. capitata and three days sooner in L. scutaria ( $5 \mathrm{~d}$ vs. $8 \mathrm{~d}$ respectively).

The absolute temperature increase above ambient in 1970 (from $26.4^{\circ} \mathrm{C}$ to $31.0^{\circ} \mathrm{C}$ ) was $4.6^{\circ} \mathrm{C}$ increase above ambient. In 2017 the increase above ambient was $2.8^{\circ} \mathrm{C}$ from $28.6^{\circ} \mathrm{C}$ to $31.4^{\circ} \mathrm{C}$. This is an increase between 1970 and 2017 ambient temperatures of $2.2^{\circ} \mathrm{C}$. To replicate realistic field conditions and test if thermal tolerances of corals have increased since 1970, temperatures were raised to $31.4^{\circ} \mathrm{C}$, a level similar to 1970 levels where significant bleaching and mortality occurred. Our results thus indicate a shift in the temperature threshold tolerance of these corals to a 30-day exposure to $31.4^{\circ} \mathrm{C}$. In 1970 , no mortality occurred for corals exposed to $29.6^{\circ} \mathrm{C}, \sim 3^{\circ} \mathrm{C}$ above the 1970 ambient (Jokiel and Coles, 1977). It is likely that a temperature increase of $4.5^{\circ} \mathrm{C}$ above the 2017 ambient would have resulted in the same level of bleaching and mortality at $31^{\circ} \mathrm{C}$ as in 1970, confirming that there was a shift upward in thermal tolerance that corresponded to the long term ambient temperature history. This corresponds to a shift upward of $\sim 2.0^{\circ} \mathrm{C}$ in thermal tolerances of Enewetak compared to Hawaiian corals that is related to the long-term temperature environments of the two regions (Coles et al., 1976).

Irradiance has been documented to have a significant influence on coral growth, bleaching, and mortality (Jokiel and Coles, 1977; Coles and Jokiel, 1978; Hoegh-Guldberg and Smith, 1989; Goenaga and Canals, 1990; Fitt and Warner, 1995; Brown et al., 1999; Jokiel, 2004). Our investigation of response across irradiance levels determined that irradiance plays a key role in the recovery of corals. Corals exposed to identical temperatures with a 50\% reduction in irradiance had a $17 \%$ lower mortality rate than those at full light exposure. However, calcification rates did not differ across irradiance levels during either the stress or recovery periods.

Although experimental conditions were carefully replicated, there were uncontrollable environmental variables that were not identical between the experimental years. There has been an increase in offshore SSTs in Hawaiian waters of $1.13^{\circ} \mathrm{C}$ over the past 47 years (Fig. 1) and the water quality in Kāne'ohe Bay has improved considerably (Table 2). At the time of the original experiment in 1970, treated sewage discharge into south Kāne'ohe Bay had been steadily increasing for the previous 20 years (Smith et al., 1981), elevating inorganic nutrients and reducing visibility by increasing plankton reproduction and growth. Coral abundance in south Kāne'ohe Bay was minimal at that time compared to the present. Following sewage diversion in 1977-78, average total nitrogen and phosphorus in the water column decreased $30-68 \%$, and inorganic nitrate+nitrite and inorganic phosphate decreased $83-86 \%$ by 2006 (Table 2 ).

These elevated nutrient levels may have contributed to the bleaching and mortality at the lower threshold temperatures that occurred in the 1970 experiments compared to 2017. Considerable 
472

473

474

475

476

477

478

479

480

481

482

483

484

485

486

487

488

489

490

491

492

493

494

495

496

497

498

499

500

501

502

503

504

505

506

507

508

509

510

511

512

513

514

515

516

517

evidence has been developed during the last decade indicating that inorganic nutrient loading of water in areas with corals plays a significant role in causing bleaching and mortality of corals at lower temperatures than occur in low nutrient environments. Controlled laboratory experiments by Cunning and Baker (2012) and Baker et al. (2018) have shown that increased dissolved inorganic nitrogen results in increased mitotic indices for symbiotic zooxanthellae, increased algal reproduction and growth, and decreasing translocation of carbon to the coral host. The final result of this process is proliferation of the symbiont at lower temperatures than would be the case in a low nutrient environment and a "parasitizing" of the coral host (Baker et al., 2018) of the energy it would otherwise receive, ultimately leading to formation of reactive oxide species that trigger coral bleaching.

This paradigm, first proposed by Wooldridge (2009), has also been substantiated by field measurements on the Great Barrier Reef (Wooldridge and Done 2009, Wooldridge et al. 2012). Comparing dissolved inorganic nitrogen (DIN) concentrations and coral bleaching thermal thresholds between inshore reefs receiving high levels of DIN from shore runoff with offshore reefs not subject to runoff. They estimated a $>50 \%$ reduction in DIN to result in a potential $\sim 2{ }^{\circ} \mathrm{C}$ reduction in bleaching threshold (Wooldridge et al., 2012). These findings based upon simultaneous observations of higher bleaching thresholds in lower DIN at different locations are remarkably similar to the higher survival and calcification rates for our experiments at the same location in water with lower DIN after nearly 50 years. Woolridge et al. (2012) suggest that low DIN $(<1 \mu \mathrm{M})$ water can confer $\sim 2^{\circ} \mathrm{C}$ of resistance to coral bleaching compared to DIN rich $(>1$ $10 \mu \mathrm{M})$ water. This is confirmed by the nutrient conditions in Kāne'ohe in the 1970s and recently. The $0.38 \mu \mathrm{M}$ for nitrate and nitrite determined by Smith et al (1981) in the south bay pre-removal of treated sewage, shows ammonium levels of $0.77 \mu \mathrm{M}$, for a total of $1.15 \mu \mathrm{Mn}$ DIN prior to 1977. Although no data for ammonium are available from Cox (2006), nitrate and nitrite totaled only $0.05 \mu \mathrm{M}$ (Table 2), and it is very likely that ammonium decreased proportionally. Earlier Smith et al. (1981) found a 34\% decrease in ammonium only a few months after cessation of sewage disposal in the south bay.

These findings thus provide a historical basis of support for the importance of nutrient levels in affecting temperature related coral bleaching thresholds, they emphasize the necessity of managing and limiting anthropogenic related sources of nutrification and eutrophication for sewage discharges from point sources and injection wells, and non-point sources from landbased runoff carrying elevated nutrients from fertilizers and animal feedlots. However, there has been little evidence on a large scale in nature that supports the research results of a reduction of nutrients ameliorating bleaching occurrence (e.g. Bruno and Valdivia, 2016). Pristine reefs along with reefs with high nutrients have been heavily impacted by bleaching. Although our results provide evidence of acclimatization/adaptation to increasing ocean temperatures and indicate that this process can be assisted by controlling nutrification, it is problematical whether corals will be able to survive the IPCC projected rapid increase in temperature levels that are well outside the range of coral survival. Most coral species are expected to exceed their upper lethal limits by 2030 (Hoegh-Guldberg et al., 2007; Veron et al., 2009; Frieler et al., 2012). Some species will be eliminated prior to other more tolerant species as we found with the low mortality of L. scutaria in this study and as reported by others (Bahr et al., 2016). A shift in species composition and coral diversity is predicted to occur as temperatures increase. 
518 Acclimatization/adaptation of $0.2-1.0^{\circ} \mathrm{C}$ per decade has been calculated as necessary to avoid 519 annual bleaching events (Donner et al., 2005). Our July-August mesocosm ambient temperatures 520 in 2017 were $2.5^{\circ} \mathrm{C}$ higher than in the experiment conducted nearly five decades earlier, a $0.48^{\circ}$

$521 \mathrm{C}$ per decade increase. However, increased bleaching tolerance may not be enough for coral 522 survival, as evidenced by the 2014/15 bleaching event that reduced coral populations in the main Hawaiian Islands by $34 \%$ (SSRI, 2017). The slow growth and recruitment of many species of corals combined with repetitive bleaching events of increasing severity and duration may lead to a catastrophic collapse (IPCC, 2016). Moreover, an analysis of worldwide bleaching events from 1980 to 2016 (Hughes et al., 2018) has determined that the median return time between pairs of bleaching events has diminished from once every 25-30 years to only six years since the early 1980s, allowing little time for coral community recovery.

Any climate change mitigation scenarios will require the reduction in use of fossil fuels and lower emissions of $\mathrm{CO}_{2}$ and other greenhouse gases. Coupling effective marine management strategies including nutrient control with acclimatization/adaptation may result in a deceleration of devastating effects from bleaching events and could extend the coral thermal tolerance threshold beyond the predicted 2030 timeline (Hoegh-Guldberg et al., 2007; Veron et al., 2009; Frieler et al., 2012).

\section{CONCLUSIONS}

- Bleaching: Bleaching occurred sooner in all species tested in 1970 as compared to 2017.

- Survivorship: Higher survivorship was observed in 2017 (92\% in L. scutaria; 83\% in M. capitata; and $60 \%$ in P. damicornis) than in the original 1970 experiment ( $40 \%$ in $L$. scutaria; $0 \%$ in M. capitata; $5 \%$ in P. damicornis) when corals were exposed to similar upper lethal temperatures $\left(\sim 31.4^{\circ} \mathrm{C}\right)$.

- Growth: Results of the 2017 study revealed prolonged exposure (31 d) to upper lethal temperatures $\left(\sim 31.4^{\circ} \mathrm{C}\right)$ suppressed calcification rates by $26-63 \%$ across tested species. Comparison of these reductions in calcification rates to the original 1970 experiment revealed even larger declines in calcification (-172.7\% in Pocillopora damicornis; $164.3 \%$ in Montipora capitata; $-99.2 \%$ in Lobactis scutaria) (Table 3).

- Recovery: Results of this current study show irradiance to play an essential role in the recovery of corals. Corals exposed to identical temperatures with a $50 \%$ reduction in irradiance had a $17 \%$ lower mortality rate than those at full light exposure.

- Species differences: No statistical differences in partial mortality or survivorship were found between heated and ambient conditions for Lobactis scutaria. Significant differences occurred in calcification, bleaching, survivorship, and partial mortality for the other three species tested.

- Ambient temperature increase: Ambient mesocosm temperatures have increased by $2.3^{\circ} \mathrm{C}$ between 1970 and 2017 with an offshore SST increase in the main Hawaiian Islands of $1.13^{\circ} \mathrm{C}$ in the past 47 years.

- Improved water quality in Kāne'ohe Bay: Inorganic nutrient levels have decreased dramatically since the removal of treated sewage disposal from the south bay in 1977-78. Available evidence indicates that the lower concentrations of nutrient pollutants, particularly dissolve organic nitrogen, have played an important role in the increased temperature tolerance of corals after nearly 50 years as was determined by these experiments. 


\section{ACKNOWLEDGEMENT}

565 We would like to thank our reviewers for their comments, which have improved the manuscript 566 tremendously. We also thank D. Coffey for his assistance in statistical analyses. This work is 567 dedicated to Dr. Paul Jokiel, who defined the coral bleaching tolerances for Hawaiian corals.

568 Without him, this work would not be possible.

570 This publication is referenced as the University of Hawai'i's School of Ocean and Earth Sciences 571 (SOEST) contribution number 10367 and Hawai'i Institute of Marine Biology (HIMB) 572 contribution number 1729. 
575

576

577

578

579

580

581

582

583

584

585

586

587

588

589

590

591

592

593

594

595

596

597

598

599

600

601

602

603

604

605

606

607

608

609

610

611

612

613

614

615

616

617

618

619

620

\section{REFERENCES}

Aeby G, Kenyon J, Maragos J, Potts D. First record of mass coral bleaching in the Northwestern Hawaiian Islands. Coral Reefs. 2003;22(3):256.

Bahr KD, Jokiel PL, Toonen RJ. The unnatural history of Kāne 'ohe Bay: coral reef resilience in the face of centuries of anthropogenic impacts. PeerJ. 2015a;3:e950.

Bahr KD, Jokiel PL, RodgerS KS. The 2014 coral bleaching and frewater flood events in Kāne 'ohe Bay, Hawai'i. PeerJ. 2015b;3;e1136.

Bahr KD, Jokiel PL, Rodgers KS. Relative sensitivity of five Hawaiian coral species to high temperature under high-pCO2 conditions. Coral Reefs. 2016:1-10.

Bahr KD, Rodgers KS, Jokiel PL. Impact of three bleaching events on the reef resiliency of Kaneohe Bay, Hawaii. Frontiers in Marine Science. 2017;4:398.

Baird A, Marshall P. Mortality, growth and reproduction in scleractinian corals following bleaching on the Great Barrier Reef. Marine Ecology Progress Series. 2002;237:133-41.

Baker DM, Freeman CJ, Wong JCY, Fogel ML, Knowlton N. Climate change promotes parasitism in a coral symbiosis. The ISME Journal 2018;12:921-930.

Bay RA, Rose NH, Logan CA, Palumbi SR. Genomic models predict successful coral adaptation if future ocean warming rates are reduced. Science advances. 2017;3(11):e1701413.

Berkelmans R, van Oppen MJH. The role of zooxanthellae in the thermal tolerance of corals: a "nugget of hope" for coral reefs in an era of climate change. Proceedings in the Royal Society B. 2006;273:2305-12.

Boesch DF, Field JC, Scavia D. The potential consequences of climate variability and change on coastal areas and marine resources: Report of the Coastal Areas and Marine Resources Sector Team, US National Assessment of the Potential Consequences of Climate Variability and Change, US Global Change Research Program 2000.

Brown B. Coral bleaching: causes and consequences. Coral reefs. 1997;16(1):S129-S38.

Brown BE, Dunne R, Ambarsari I, Le Tissier M, Satapoomin U. Seasonal fluctuations in environmental factors and variations in symbiotic algae and chlorophyll pigments in four Indo-Pacific coral species. Marine Ecology Progress Series. 1999:53-69.

Brown BE, Dunne RP, Warner ME, Ambarsari I, Fitt WK, Gibb SW, Cummings, DG. Damage and recovery of Photosystem II during a manipulative field experiment on solar bleaching in the coral Goniastrea aspera. Marine Ecology Progress Series. 2000:117-24.

Bruno JF, Valdivia A. Coral reef degradation is not correlated with local human population density. Scientific Reports. 2016;6:29778.

Carilli J, Donner SD, Hartmann AC. Historical temperature variability affects coral response to heat stress. PLoS One. 2012;7(3):e34418.

Castillo KD, Ries JB, Weiss JM, Lima FP. Decline of forereef corals in response to recent warming linked to history of thermal exposure. Nature Climate Change. 2012;2(10):756-60.

Coles SL. 1973. Some effects of temperature and related physical factors on Hawaiian reef corals. Ph.D. Dissertation Dept. of Zoology. University of Hawai'i, Honolulu.

Coles SL, editor Coral bleaching that occurred off Kahe Point and Nanakuli, Oah' $\mathrm{u}$ in 2015 and follow-up observations made in 2016. AAAS Pacific Division; 2017; Waimea, Hawai' $i$.

Coles SL, Jokiel PL. Effects of temperature on photosynthesis and respiration in hermatypic corals. . Marine Biology. 1977;43(3):209-16.

Coles SL, Jokiel PL. Synergistic effects of temperature, salinity and light on the hermatypic coral Montipora verrucosa. Marine Biology. 1978;49(3):187-95. 
621

622

623

624

625

626

627

628

629

630

631

632

633

634

635

636

637

638

639

640

641

642

643

644

645

646

647

648

649

650

651

652

653

654

655

656

657

658

659

660

661

662

663

664

665
Coles SL, Brown BE. Coral bleaching — capacity for acclimatization and adaptation. Advances in Marine Biology. 2003;46:183-223.

Coles SL, Riegl BM. Thermal tolerances of reef corals in the Gulf: A review of the potential for increasing coral survival and adaptation to climate change through assisted translocation. Marine pollution bulletin. 2013;72(2):323-32.

Coles SL, Jokiel PL, Lewis CR. Thermal tolerance in tropical versus subtropical pacific reef corals. Pacific Science. 1976;30(2):159-66.

Couch CS, Burns JHR, Liu G, Steward K, Gutlay TN, Kenyon J, Eakin CM, Kosaki RK. Mass coral bleaching due to unprecedented marine heatwave in Papahānaumokuākea Marine National Monument (Northwestern Hawaiian Islands). PloS one. 2017;12(9):e0185121.

Cox EF, Ribes M, Kinzie III RA. Temporal and spatial scaling of planktonic responses to nutrient inputs into a subtropical embayment. Marine Ecology Progress Series. 2006;324:1935.

Cunning R, Baker AC. Excess algal symbionts increase the susceptibility of reef corals to bleaching. Nature Climate Change 2013; 3:259-262.

Darling ES, Alvarez-Filip L, Oliver TA, McClanahan TR, Côté IM. Evaluating life-history strategies of reef corals from species traits. Ecology Letters. 2012;15(12):1378-86.

Donner SD, Skirving WJ, Little CM, Oppenheimer M, Hoegh-Guldberg O. Global assessment of coral bleaching and required rates of adaptation under climate change. Global Change Biology. 2005;11(12):2251-65.

Eakin M, Liu G, Gomez A, De la Cour J, Heron S, Skirving W. Global coral bleaching 20142017: status and an appeal for observations. Reef Encounter. 2016;31:20-6.

Fisher R, O'leary RA, Low-Choy S, Mengersen K, Knowlton N, Brainard RE, Caley MJ. Species richness on coral reefs and the pursuit of convergent global estimates. Current Biology. 2015;25(4):500-505.

Fitt W, Warner M. Bleaching patterns of four species of Caribbean reef corals. The Biological Bulletin. 1995;189(3):298-307.

Fitt WK, Brown BE, Warner ME, Dunne RP. Coral bleaching: interpretation of thermal tolerance limits and thermal thresholds in tropical corals.Coral Reefs. 2001;20:51-65.

Franklin EC, Jokiel PL, Donahue MJ. Predictive modeling of coral distribution and abundance in the Hawaiian Islands. Marine Ecology Progress Series. 2013;481:121-32.

Frieler K, Meinshausen M, Golly A, Mengel M, Lebek K, Donner SD, Hoegh-Guldberg O. Limiting global warming to 2 [thinsp][deg] $\mathrm{C}$ is unlikely to save most coral reefs. Nature Climate Change. 2013;3(3):165-70.

Gates RD, Edmunds PJ. The physiological mechanisms of acclimatization in tropical reef corals. American Zoologist. 1999;39(1):30-43.

Gittenberger A, Reijnen BT, Hoeksema BW. A molecularly based phylogeny reconstruction of mushroom corals (Scleractinia Fungiidae) with taxonomic consequences and evolutionary

Glynn PW. Coral reef bleaching in the 1980s and possible connections with global warming. Trends in Ecology \& Evolution. 1991;6(6):175-9.

Glynn PW. Coral reef bleaching: ecological perspectives. Coral Reefs. 1993;12:1-17.

Goenaga C, Canals M. Island-wide coral bleaching in Puerto Rico. Caribbean Journal of Science. 1990;26:171-5.

Graham NE. Decadal-scale climate variability in the tropical and North Pacific during the 1970s and 1980s: Observations and model results. Climate Dynamics. 1994;10(3):135-62. 
666

667

668

669

670

671

672

673

674

675

676

677

678

679

680

681

682

683

684

685

686

687

688

689

690

691

692

693

694

695

696

697

698

699

700

701

702

703

704

705

706

707

708

709
Grottoli AG, Rodrigues LJ, Juarez C. Lipids and stable carbon isotopes in two species of Hawaiian corals, Porites compressa and Montipora verrucosa, following a bleaching event. Marine Biology. 2004;145(3).

Guest JR, Baird AH, Maynard JA, Muttaqin E, Edwards AJ, Campbell SJ, Yewdall K, Affendi YA, Chou LM. Contrasting patterns of coral bleaching susceptibility in 2010 suggest an adaptive response to thermal stress. PloS one. 2012;7(3):e33353.

Henry L, Hart M. Regeneration from Injury and Resource Allocation in Sponges and Corals - a Review. Internat. Rev. Hydrobiol. 2005;90(2):125-158.

Hoegh-Guldberg O. Climate change, coral bleaching and the future of the world's coral reefs. Marine and freshwater research. 1999;50(8):839-66.

Hoegh-Guldberg O, Smith GJ. The effect of sudden changes in temperature, light and salinity on the population density and export of zooxanthellae from the reef corals Stylophora pistillata Esper and Seriatopora hystrix Dana. Journal of Experimental Marine Biology and Ecology. 1989;129(3):279-303.

Hoegh-Guldberg O, Mumby PJ, Hooten AJ, Steneck RS, Greenfield P, Gomez E, Harvell CD, Sale PF, Edwards AJ, Caldeira K, Knowlton N, Eakin CM, Iglesias-Prieto R, Muthiga N, Bradbury RH, Dubi A, Hatziods ME. Coral reefs under rapid climate change and ocean acidification. Science. 2007;318(5857):1737-42.

Hughes TP, Baird AH, Bellwood DR, Card M, Connolly SR, Folke C, Grosberg R, HoeghGuldberg O, Jackson JB, Kleypas J, Lough JM, Marshall P, Nyström M, Palumbi SR, Pandolfi JM, Rosen B, Roughgarden J. Climate change, human impacts, and the resilience of coral reefs. science. 2003;301(5635):929-33.

Hughes TP, Kerry JT, Álvarez-Noriega M, Álvarez-Romero JG, Anderson KD, Baird AH, Babcock RC, Beger M, Bellwood DR, Berkelmans R, Bridge TC, Butler IR, Byrne M, Cantin NE, Comeau S, Connolly SR, Cumming GS, Dalton SJ, Diaz-Pulido G, Eakin CM, Figueira WF, Gilmour JP, Harrison HB, Heron SF, Hoey AS, Hobbs JAP, Hoogenboom MO, Kennedy EV, Kuo C, Lough JM, Lowe RJ, Liu G, McCulloch MT, Malcolm HA, McWillliam MJ, Pandolfi JM, Pears RJ, Pratchett MS, Schoepf V, Simpson T, Skirving WJ, Sommer B, Torda G, Wachenfeld DR, Willis BL, Wilson SK. Global warming and recurrent mass bleaching of corals. Nature. 2017;543(7645):373-7.

Institute SSR. Coral Bleaching Recovery Plan: Identifying Management Responses to Promote Coral Recovery in Hawai'i. 2017.

Intergovernmental Panel on Climate Change. Climate Change 2014-Impacts, Adaptation and Vulnerability: Regional Aspects: Cambridge University Press; 2014.

Jokiel PL. Temperature stress and coral bleaching. Coral health and disease: Springer; 2004. pp. 401-25.

Jokiel PL, Coles SL. Effects of heated effluent on hermatypic corals at Kahe Point, Oahu. Pacific Science. 1974;28:1-18.

Jokiel PL, Coles SL. Effects of temperature on the mortality and growth of Hawaiian reef corals. Marine Biology. 1977;43(3):201-8.

Jokiel PL, Coles SL. Response of Hawaiian and other Indo-Pacific reef corals to elevated temperature. Coral reefs. 1990;8(4):155-62

Jokiel PL, Brown EK. Global warming, regional trends and inshore environmental conditions influence coral bleaching in Hawai'i. Global Change Biology 2004;10(10):16277-1641. 
723

724

725

726

727

728

729

730

731

732

733

734

735

736

737

738

739

740

741

742

743

744

745

746

747

748

749

750

751

752

753

754

Jokiel PL, Coles SL, Guinther EB, Key GS, Smith SV, Townsley SJ. 1975. Effects of Thermal Loading on Hawaiian Reef Corals. prepared for Office of Research and Monitoring EPA Report pp. 285.

Jokiel PL, Maragos JE, Franzisket L. Coral growth: buoyant weight technique. Eds Johannes DR. Coral Reefs: Research Methods; Monographs on Oceanographic Methodology; Unesco, Paris. 1978;529-42.

Jokiel PL, Bahr KD, Rodgers KS. Low cost ocean acidification system for high-flow mesocosm and field applications on coral reefs. . Limnology and Oceanography: Methods. 2014.

Kenyon JC, Aeby GS, Brainard RE, Chojnacki JD, Dunlap MJ, Wilkinson CB. Mass coral bleaching on high-latitude reefs in the Hawaiian. Proceedings of 10th International Coral Reef Symposium; 2006.

Kramer KI, Cotton SP, Lamson MR, Walsh WJ. Bleaching and catastrophic mortality of reefbuilding corals along west Hawai' $i$ island: findings and future directions. Proceedings of the 13th International Reef Symposium, Honolulu. 2016;219-32

Liu G, Heron SF, Mark Eakin C, Muller-Krager FE, Vega-Rodriguez M, Guild LS, De la Cour JL, Geiger EF, Skirving WJ, Burgess TFR, Strong AE, Harris A, Maturi E, Ignatov A, Sapper J, Li J, Lynds S. Remote sensing of reef scale-thermal stress monitoring of coral reef systems. New 5-km global products from NOAA Coral reef Watch. Remote Sens. 2014;6(11):11579-606.

Logan CA, Dunne JP, Eakin CM, Donner SD. 2014. Incorporating adaptive responses into future projections of coral bleaching. Global Climate Change. https://doi.org/10.1111/gcb.12390.

Matz MV, Treml EA, Agayamova GV, Bay LK. 208. Potential and limits for radid genetic adaptation to warming a Great Barrier Reef coral. Plos Genetics.

https://doi.org/10.1371/journal.pgen.1007220

Maragos J. Coral growth: geometrical relationships. Eds Stoddart, DR and Johannes, RE, Handbook of coral reef research methods, Unesco, Paris. 1978;5:543-50.

Maynard J, Anthony K, Marshall P, Masiri I. Major bleaching events can lead to increased thermal tolerance in corals. Marine Biology. 2008;155(2):173-82.

Mcallister DE. What is the status of the world's coral reef fishes. Sea Wind. 1991;5(1):14-8.

Oliver T, Palumbi S. Do fluctuating temperature environments elevate coral thermal tolerance? Coral Reefs. 2011;30(2):429-40.

Pratchett MS, McCowan D, Maynard JA, Heron SF. Changes in bleaching susceptibility among corals subject to ocean warming and recurrent bleaching in Moorea, French Polynesia. PLoS one. 2013;8(7):e70443.

Riegl B. Climate change and coral reefs: different effects in two high-latitude areas (Arabian Gulf, South Africa). Coral reefs. 2003;22(4):433-46.

Rodgers KS, Bahr KD, Jokiel PL, Donà AR. Patterns of bleaching and mortality following widespread warming events in 2014 and 2015 at the Hanauma Bay Nature Preserve,Hawai 'i. PeerJ. 2017;5:e3355.

Smith SV. Coral reef area and the contribution of reefsto processes of the world's oceans. Nature. 1978;273:225-6.

Smith SV, Kimmerer WJ, Laws EA, Brock RE, Walsh TW. Kaneohe Bay sewage diversion experiment: perspectives on ecosystem responses to nutritional perturbation. Pacific 
755

762

763

764

765

766

767

768

769

770

771

772

773

774

775

776

777

778

779

780

781
Science. 1981;35(4):279-395. Vaughan TW. Reef coral of the Bahamas and of Southern Florida. Carn Inst Wash Yearbook

Stimson J, Sakai K, Sembali H. Interspecific comparison of the symbiotic relationship in corals with high and low rates of bleaching-induced mortality. Coral Reefs. 2002;21:409-21.

Vaughan TW. The recent Madreporaria of southern Florida. Carnegie Institiution of Washington Yearbook (1910). 1911;9:135-44.

Veron JE, Hoegh-Guldberg O, Lenton T, Lough JM, Obura DO, Pearce-Kelly P, Sheppard CR, Spalding M, Stafford-Smith MG, Rogers AD. The coral reef crisis: The critical importance of $<350$ ppm CO 2. Marine pollution bulletin. 2009;58(10):1428-36.

Wilkinson CR, Lindén O, Cesar HS, Hodgson G, Rubens J, Strong AE. Ecological and socioeconomic impacts of 1998 coral mortality in the Indian Ocean: An ENSO impact and a warning of future change? Ambio. 1999;28(2):188.

Williams EH, Bunkely-Williams L. The world-wide coral reef bleaching cycle and related sources of coral mortality. Atoll Research Bulletin. 1990;355:1-71.

Woolridge SA. A new conceptual model for the warm-water breakdown of the coral-algae endosymbionts. Marine and Freshwater Research. 2009;60(6):483-96.

Woolridge SA, Done TJ. Improved water quality can ameliorate effects of climate change on corals. Ecological Applications. 2009;19(6):1492-99.

Woolridge SA, Done TJ, Thomas CR, Gordon I, Marshall PA, Jones RN. Safeguarding coastal communities on the central Great Barrier Reef (Australia) against climate change: realizable local and global actions. Climatic Change. 2012;112(3):945-61.

Yonge CM, Nicholls AG. Studies on the physiology of corals. IV. The structure, distribution and physiology of the zooxanthellae. Great Barrier Reef Expedition 1928-29 Scientific Reports. 1931;1:135-76. British Museum.

Xu S, Yu K, Tao S, Wu CC, Wang Y, Jiang W, Wang S, Shen CC. Evidence for the thermal bleaching of Porites corals from 4.0 ka B.P. in the Northern South China Sea. Journal of Geophysical Research. 2018;123(1):79-94. 
Figure 1 (on next page)

Offshore sea surface temperatures in Hawai'i

Sea surface temperatures (SST) for offshore Hawai'i using IGOSS-NMC temperature data (1992-2014) and corrected NMFS data (1956-1992) for Koko Head, O'ahu between 19562017. 


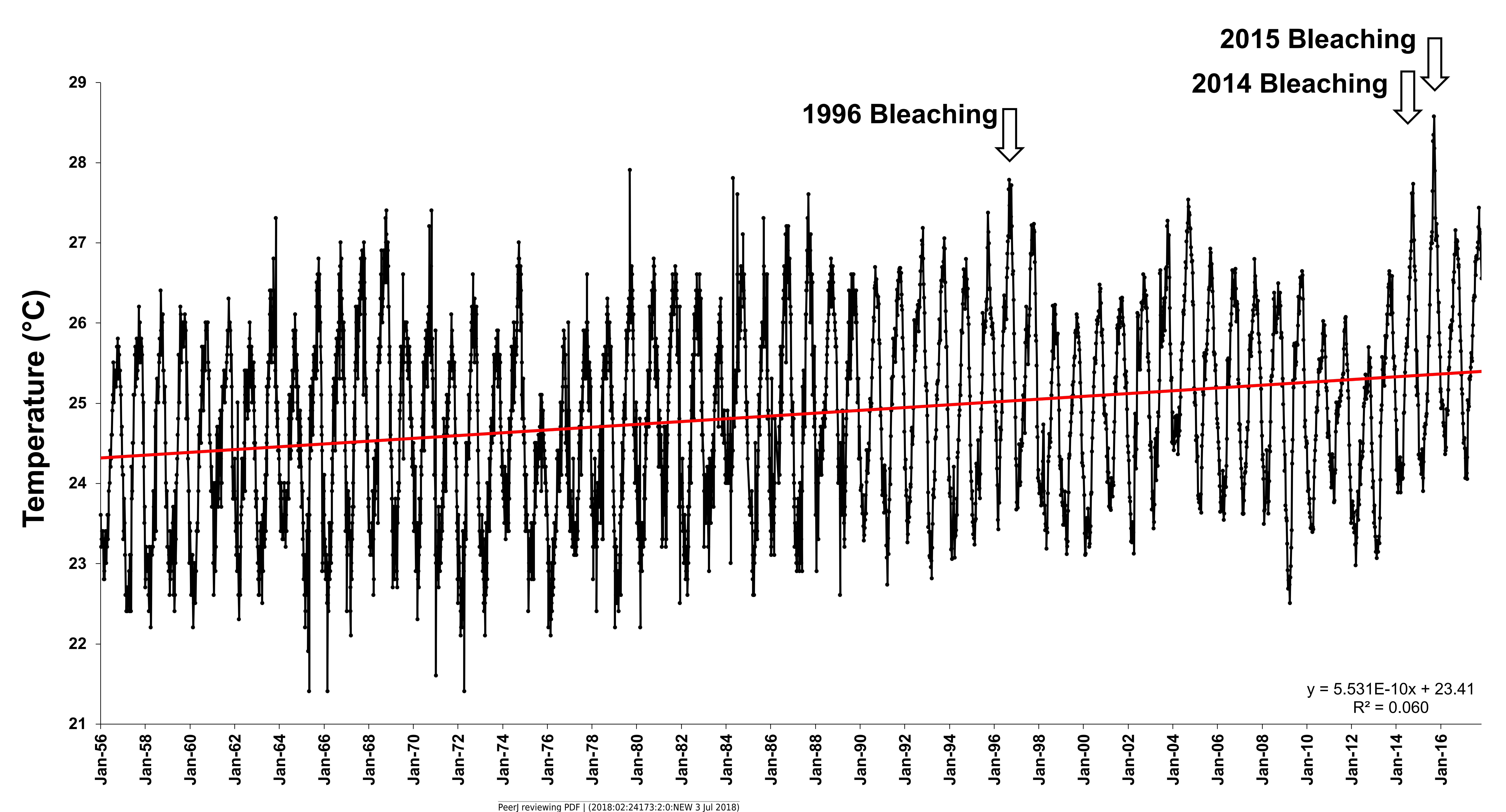


Figure 2 (on next page)

\section{Coral calcification response}

Calcification $\left(\mathrm{mm} \mathrm{d}^{-1}\right)$ of tested coral species Lobactis scutaria, Montipora capitata, Pocillopora damicornis, and Porites compressa under ambient (blue) and heated (red) temperatures at the end of the 31-day stress period (red shaded; 11 July - 11 Aug 2017). Error bars are SE of mean response per treatment tank $(n=3)$. Data are pooled across irradiance regimes. $*$ denotes significant statistical difference. 


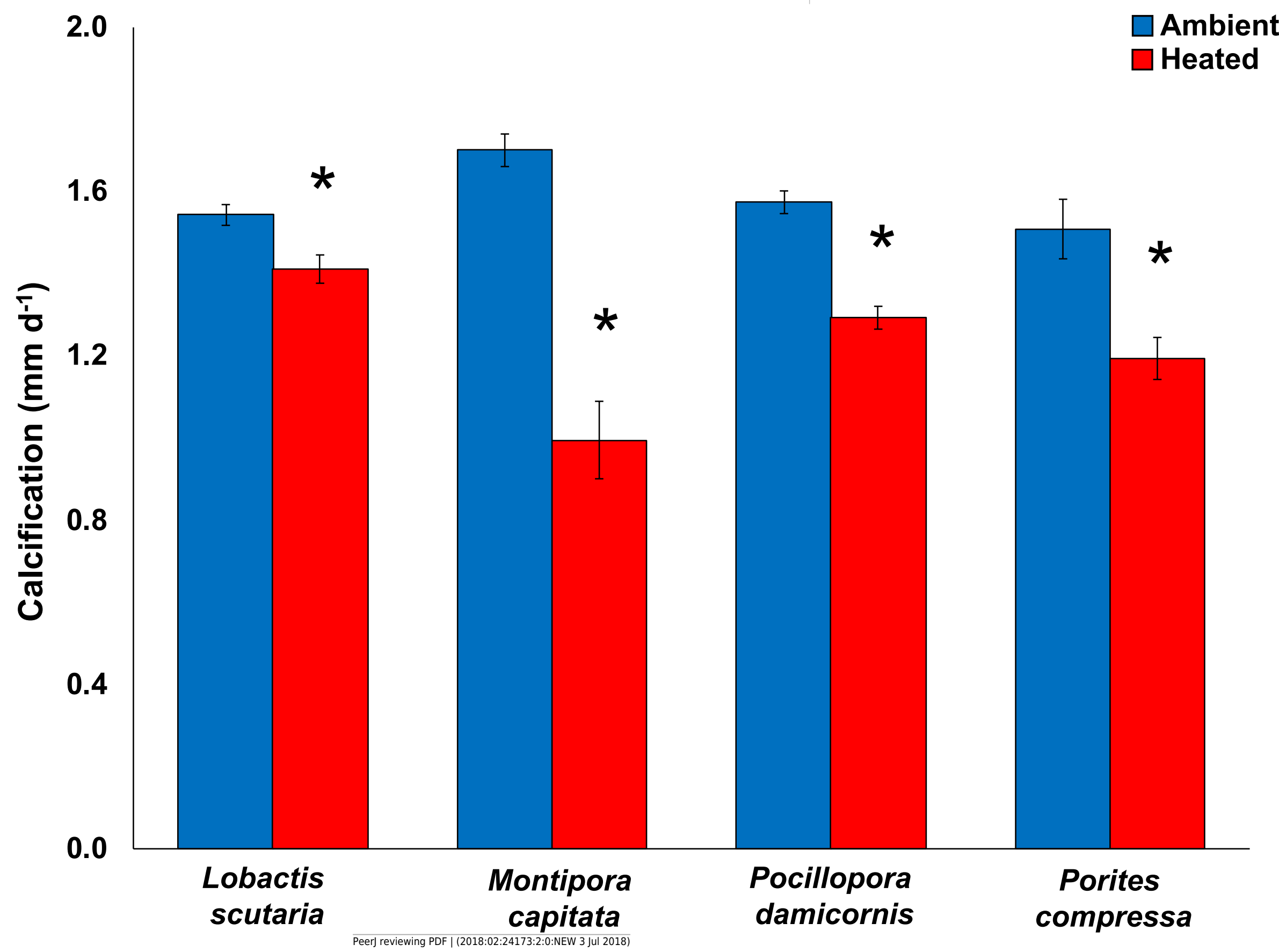


Figure 3 (on next page)

2017 Coral partial mortality

Partial mortality of tested coral species Lobactis scutaria (A.), Montipora capitata (B.), Pocillopora damicornis (C.), and Porites compressa (D.) under ambient (blue) and heated (red) temperatures in unshaded and shaded (grey panels) regimes during the 30 day stress (red shaded; 11 July - 11 Aug 2017) and following recovery period (11 Aug - 11 Sept 2017). 


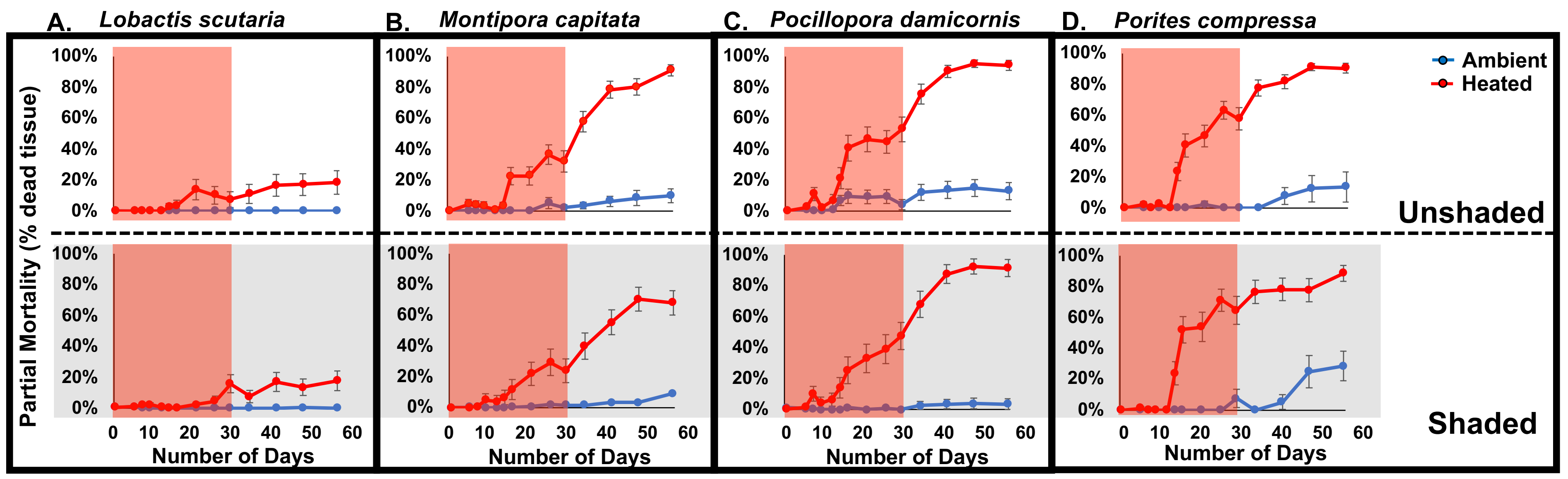


Figure 4 (on next page)

1970 vs. 2017 coral calcification

Calcification of tested coral species during 1970 (white circle) and 2017 (black square) across experimental temperatures. Error bars for 2017 data are SE of mean $(n=3)$. 


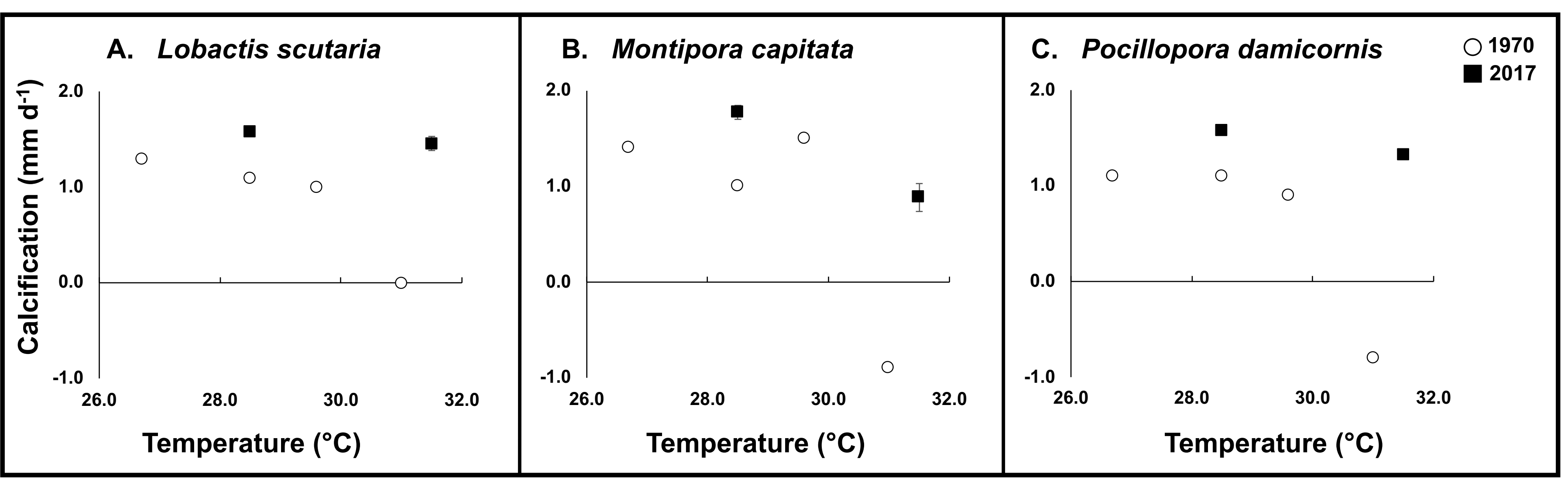


Figure 5 (on next page)

1970 vs. 2017 Coral survivorship

Survivorship (number of individuals; > 95\% partial mortality) of tested coral species (A. Lobactis scutaria; B. Montipora capitata; C. Pocillopora damicornis) at 2017 summer ambient temperatures $\left(28.7^{\circ} \mathrm{C}\right.$; blue square), and current heated treatments $\left(31.4^{\circ} \mathrm{C}\right.$; red circle) and in 1970 ( $31^{\circ} \mathrm{C}$; black triangles). No mortality was observed in 1970 summer ambient treatment $\left(26.4^{\circ} \mathrm{C}\right.$; Jokiel and Coles, 1977) . Mean survivorship values were used for 2017 and error bars are SE of mean $(n=3)$. 


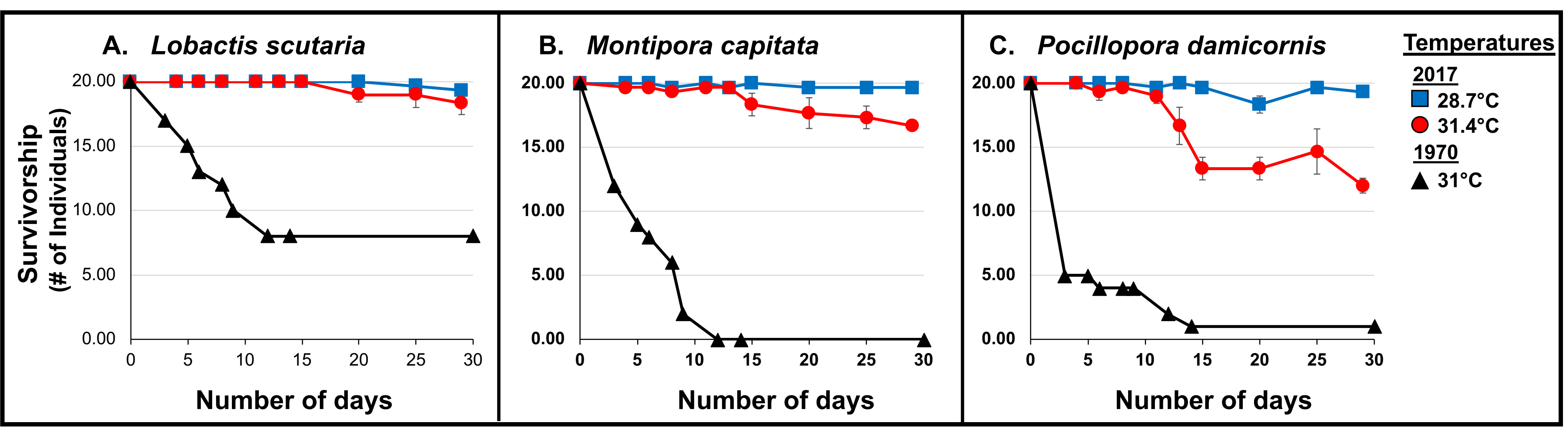


Figure 6 (on next page)

1970 vs. 2017 Coral visual assessment

Comparison of visual assessment scores representing mean "health" ( $1=$ normal; $2=$ pale; 3 = bleached, 4= dead) in 1970 and 2017 (full sun only) during the $31 \mathrm{~d}$ stress period under heated conditions (2017 red circle and 1970 black triangle) and ambient temperatures (2017 blue square and black diamond) in Lobactis scutaria (A.) Montipora capitata (B.) and Pocillopora damicornis (C.). Error bar represent SE of the mean $(n=20)$. Examples of visual assessment scoring are provided in Fig. S1. 


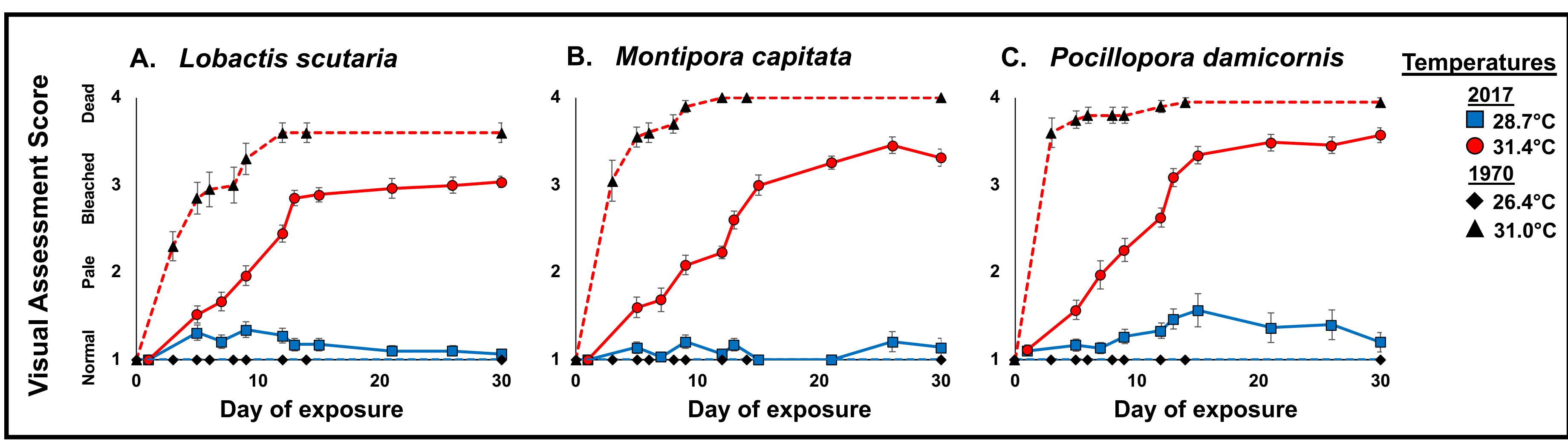




\section{Table 1 (on next page)}

2017 experimental conditions

Environmental characteristics during the $30 \mathrm{~d}$ stress period (11 July - 11 Aug 2017). 
1 Table 1. Environmental characteristics during the $30 \mathrm{~d}$ stress period (11 July - 11 Aug 2017).

\begin{tabular}{|c|c|c|c|c|c|c|c|c|c|c|}
\hline \multirow[t]{2}{*}{ Treatment } & \multirow{2}{*}{$\begin{array}{c}\text { Tank } \\
\text { Number }\end{array}$} & \multicolumn{2}{|c|}{$\begin{array}{c}\text { Mid-day } \\
\text { temperature }\end{array}$} & \multicolumn{2}{|c|}{ Salinity } & \multicolumn{2}{|c|}{$\mathbf{D O}\left(\mathrm{mg} \mathrm{L}^{-1}\right)$} & \multicolumn{3}{|c|}{$\begin{array}{c}\text { Irradiance } \\
\left(\mu \mathrm{mol} \text { photons } \mathrm{m}^{-2} \mathrm{~s}^{-1}\right)\end{array}$} \\
\hline & & Mean & $\pm \mathrm{SE}$ & Mean & $\pm \mathbf{S E}$ & Mean & $\pm \mathbf{S E}$ & Mean & $\pm \mathrm{SE}$ & Max \\
\hline \multirow[t]{3}{*}{ Ambient } & 5 & 28.46 & \pm 0.02 & 34.65 & \pm 0.06 & 10.40 & \pm 0.38 & \multirow{6}{*}{749.18} & \multirow{6}{*}{ \pm 23.42} & \multirow{6}{*}{1745.00} \\
\hline & 7 & 28.54 & \pm 0.03 & 34.66 & \pm 0.06 & 10.43 & \pm 0.61 & & & \\
\hline & 12 & 28.83 & \pm 0.03 & 34.64 & \pm 0.05 & 10.43 & \pm 0.46 & & & \\
\hline \multirow[t]{3}{*}{ Heated } & 4 & 31.46 & \pm 0.02 & 34.67 & \pm 0.06 & 9.46 & \pm 0.55 & & & \\
\hline & 8 & 31.40 & \pm 0.02 & 34.68 & \pm 0.06 & 9.53 & \pm 0.41 & & & \\
\hline & 11 & 31.35 & \pm 0.02 & 34.68 & \pm 0.06 & 9.30 & \pm 0.40 & & & \\
\hline
\end{tabular}




\section{Table 2 (on next page)}

1970 vs. 2017 environmental conditions

Comparison of environmental parameters in south Kāne'ohe Bay during experimental periods. 
1 Table 2. Comparison of environmental parameters in south Kāne'ohe Bay during experimental 2 periods.

\begin{tabular}{|c|c|c|}
\hline Parameter & $\mathbf{1 9 7 0}^{*}$ & $\mathbf{2 0 1 7}^{* *}$ \\
\hline Temperature $\left({ }^{\circ} \mathrm{C}\right)$ & $26.40 \pm 0.03$ & $28.70 \pm 0.02$ \\
\hline Salinity $(\mathrm{ppt})$ & $34.9 \pm 0.09$ & $35.1 \pm 0.04$ \\
\hline PAR $(\mathrm{k})$ & 0.37 & $0.29 \pm 0.01$ \\
\hline Total N $(\mu \mathrm{Mol} / \mathrm{L})$ & 10.60 & $7.38 \pm 1.45$ \\
\hline Total P $(\mu \mathrm{Mol} / \mathrm{L})$ & 1.01 & $0.32 \pm 0.07$ \\
\hline Nitrate + Nitrite $(\mu \mathrm{Mol} / \mathrm{L})$ & 0.38 & $0.05 \pm 0.12$ \\
\hline Phosphate $(\mu \mathrm{Mol} / \mathrm{L})$ & 0.48 & $0.08 \pm 0.004$ \\
\hline
\end{tabular}

$3 *$ Temperature data taken from 1970 experiments, all other parameters from Smith et al. 1981

$4 * *$ Temperature data taken from 2017 experiment, all other parameters from Cox et al. 2006

5 (CISNet data). Mean \pm SE. 


\section{Table 3(on next page)}

1970 vs. 2017 summary comparison

Percent change of calcification and survivorship between ambient and elevated temperature conditions at the end of the experiment ( $n=20$ in 1970 for $30 d, n=60$ in 2017 for 31 d). 
Table 3. Percent change of calcification and survivorship between ambient and elevated temperature conditions at the end of the experiment ( $n=20$ in 1970 for $30 d, n=60$ in 2017 for 31 d).

\begin{tabular}{|c|c|c|c|c|}
\hline & \multicolumn{2}{|c|}{ Calcification } & \multicolumn{2}{c|}{ Survivorship } \\
\hline Species & $\mathbf{1 9 7 0}$ & $\mathbf{2 0 1 7}$ & $\mathbf{1 9 7 0}$ & $\mathbf{2 0 1 7}$ \\
\hline Lobactis scutaria & $-99.23 \%$ & $-7.84 \%$ & $40 \%$ & $92 \%$ \\
\hline Montipora capitata & $-164.29 \%$ & $-50.16 \%$ & $0 \%$ & $83 \%$ \\
\hline Pocillopora damicornis & $-172.73 \%$ & $-16.04 \%$ & $5 \%$ & $60 \%$ \\
\hline
\end{tabular}

